\title{
The effect of Helicobacter pylori eradication on C-reactive protein: results from a meta-analysis
}

Jun Watanabe, Kazuhiko Kotani

Division of Community and Family Medicine, Jichi Medical University, Shimotsuke city, Japan

Submitted: 16 July 2020; Accepted: 7 November 2020

Online publication: 21 March 2021

Arch Med Sci 2022; 18 (4): 958-964

DOI: https://doi.org/10.5114/aoms/130288

Copyright $\odot 2022$ Termedia \& Banach

\section{Abstract}

Introduction: Helicobacter pylori is a bacterium that causes chronic gastroduodenal infection and affects various systemic diseases. An increase in the blood level of C-reactive protein (CRP; a systemic inflammatory marker), at a low-grade chronic inflammation level, is observed in cases of infection. However, the effect of $H$. pylori eradication on CRP remains undetermined. Therefore, we aimed to evaluate the circulating CRP levels in eradicated patients through a meta-analysis.

Material and methods: The PubMed database was searched from its inception to June 2020. Studies that described the CRP levels following $H$. pylori eradication were collected. A random-effects meta-analysis was then performed using inverse variance with standardized mean difference.

Results: A total of 10 eligible studies (642 subjects in total) were available. The median age in the studies was 49.9 years. The CRP level was 6.0 (median) $\mathrm{mg} / \mathrm{l}$ before $H$. pylori eradication and 5.8 (median) $\mathrm{mg} / \mathrm{l}$ after eradication. From the results of the overall meta-analysis, there was found to be a significant reduction in the CRP levels with $\mathrm{H}$. pylori eradication (standardized mean difference: $-0.64 ; 95 \%$ confidence interval: -1.02 to -0.27$)$. The result was not similarly confirmed in a subanalysis of the available randomized controlled trials.

Conclusions: Weak evidence exists regarding the effects of $H$. pylori eradication on CRP levels. Further research is called for.

Key words: anti-bacterial therapy, C-reactive protein, Helicobacter pylori, inflammation.

\section{Introduction}

The bacterium Helicobacter pylori causes gastroduodenal inflammation [1]. H. pylori infection is present in $28-84 \%$ of populations around the world [2]. The precancerous lesions of chronic gastritis are well known to be caused by H. pylori infection [3-5]. H. pylori eradication using a regimen containing anti-bacterial agents is useful not only for healing gastroduodenal ulcers but also for preventing gastric cancer [6].

C-reactive protein (CRP), produced in the liver and released into blood, is a representative marker reflecting systemic inflammation [7]. This protein is increased not only in acute but also in chronic diseases, and its slight change in chronic diseases at a low-grade subclinical level has pathophysiological relevance [7-9]. In H. pylori infection, a low-grade chronic increase in circulating inflammatory markers, especially CRP, is

\author{
Corresponding author: \\ Prof. Kazuhiko Kotani \\ Division of Community \\ and Family Medicine \\ Jichi Medical University \\ 3311-1 Yakushiji \\ 329-0498 Shimotsuke city \\ Japan \\ Phone: +81.285 .58 .7394$ \\ E-mail: kazukotani@jichi.ac.jp
}


observed [10]. Such chronic inflammation is also known to initiate and exacerbate various systemic pathologies [11]. H. pylori infection is indicatively related to other gastric and even extra-gastric diseases, including gastric mucosa-associated lymphoid tissue lymphoma, functional dyspepsia, idiopathic thrombocytopenic purpura, iron deficiency anemia, chronic urticaria, metabolic disorder, ischemic heart disease, cognitive impairment, and neurodegeneration [6, 12-16].

The clinical manifestations of some diseases may be improved after $H$. pylori eradication in relation to the CRP levels $[4-6,17,18]$. As the CRP levels are typically low in such inflammatory states, changes in them may be overlooked. The effect of $H$. pylori eradication on CRP remains undetermined; accordingly, the present study was designed to evaluate the effect of $H$. pylori eradication on circulating CRP levels through a meta-analysis.

\section{Material and methods}

The relevant literature was searched using the PubMed database from its inception to June 3 , 2020. The following keywords were used to search: ("Helicobacter pylori"[Mesh] OR "Helicobacter pylori”[tiab] OR “H. pylori”[tiab]) AND ("C-Reactive Protein"[Mesh] OR "c-reactive protein"[tiab] OR "CRP”[tiab]) AND ("eradicat" [tiab]). Studies that focused on the effect of $H$. pylori eradication on CRP were included. Non-English-language and non-adult studies were excluded.

First, all candidate articles searched were independently screened according to the title and abstract. Original articles that did not focus on $H$. pylori and CRP were excluded. Second, the full text of potentially relevant abstracts was evaluated for eligibility. Original articles that did not focus on $H$. pylori and CRP were further excluded. When the researchers' opinions matched, the articles were considered eligible. The agreement between the two researchers was determined by the $\kappa$ value. The eligibility was judged based on the two researchers' opinions. Third, summary tables of the respective articles were extracted and created.

The risk of bias was independently assessed using Risk of Bias (RoB) 2 [19] for randomized studies and the Newcastle-Ottawa Quality Assessment Scale (NOS) [20] for non-randomized studies. RoB 2 was assessed as described in the Cochrane handbook for the following six domains: random sequence generation, allocation concealment, blinding of participants and personnel, blinding of outcome assessment, incomplete outcome data, and selective reporting. Each domain was classified into one of three categories (high risk, low risk, some concerns). The NOS assigns a maximum of 9 points to studies of the highest quality according to three quality parameters: selection, comparability and outcome; high score means better quality. Any disagreement of the assessment by the two researchers was resolved by discussion.

The standardized mean difference (SMD) with the $95 \%$ confidence interval $(\mathrm{Cl})$ of the mean change in the CRP levels after $H$. pylori eradication was calculated as described in the Cochrane handbook [21]. The meta-analysis was performed by comparing each individual case before and after eradication, regardless of study design, because the CRP levels differ among individuals. Similar analyses were performed in earlier studies [22-24]. The statistical heterogeneity was evaluated by visual inspection of the forest plots and calculating the $R^{2}$ statistic $\left({ }^{2}\right.$ values of $0-40 \%$ : might not be important; 30-60\%: may represent moderate heterogeneity; 50-90\%: may represent substantial heterogeneity; $75-100 \%$ : may represent considerable heterogeneity) [21]. When there was substantial heterogeneity $\left(R^{2}>50 \%\right)$, the potential reason for the heterogeneity was assessed using a subgroup analysis. The potential publication bias was assessed by visual inspection of the funnel plot [21]. The meta-analysis was performed with a random-effects model using the genetic inverse method in the Review Manager 5.4 software program of RevMan 2020.

\section{Results}

Figure 1 shows the process of selection of articles that reported the effect of $H$. pylori eradication on CRP. After the first step, a total of 44 records were searched, and 15 articles were considered candidates (inter-reader agreement, $\kappa=0.894$ ). At the second step, four articles were excluded because these articles did not meet the criteria. Eleven studies were then identified in quantitative synthesis (inter-reader agreement, $\kappa=1.0$ ) [25-35]. Finally, 10 studies (total of 642 subjects) were meta-analyzed, as 1 article [30] did not report important measures, such as the standard deviation, range, or standard error of the CRP levels.

Table I shows the summary of the reviewed studies. Four studies were reported from the Middle East (Turkey [27], Iran [32], Egypt [33, 35]), 4 from Europe (Spain [25, 34], Italy [26], the Netherlands [29]), 1 from the United States [31] and 1 from Korea [28]. The study design consisted of 2 randomized controlled trials (RCTs), 2 cohort studies, 2 case-controlled studies and 4 before-after studies. The age reported in the reviewed studies was 49.9 (median (range: 44.7-56.0)) years. The CRP level was 6.0 (median (range: 0.0028310)) $\mathrm{mg} / \mathrm{l}$ before $H$. pylori eradication and 5.8 (median (range: 0.0026-100)) mg/l after it. The periods of eradication ranged from 7 to 14 days. The 


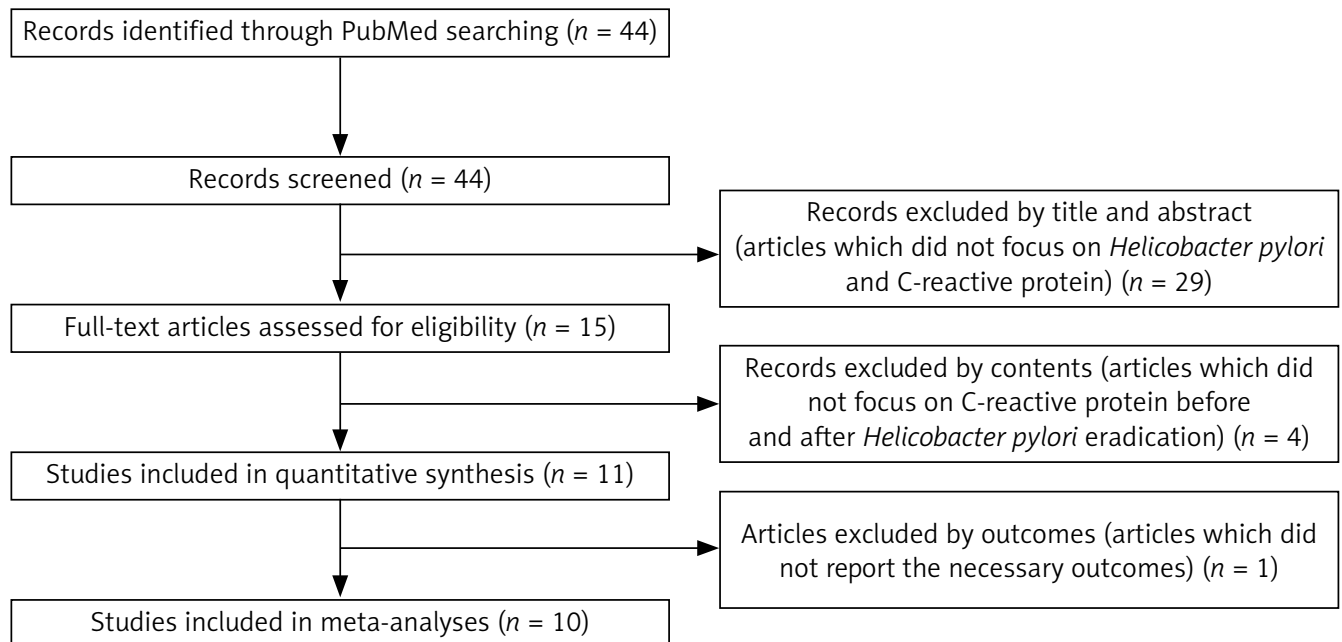

Figure 1. Flow chart of article selection

H. pylori eradication rate was $96.4 \%$ (median (range: $73.3-100 \%)$ ). The follow-up period, meaning the interval period to examined CRP levels before and after eradication, was 3 (median (range: 1.5-24)) months.

Tables II and III show the quality scores for the reviewed randomized and non-randomized studies, respectively. The overall risks of bias in 2 RCTs were classified into some concerns due to unclear random sequence generation and reporting bias. The quality assessment of 8 non-RCTs were moderate scores in the range of 5-6. Regarding publication bias, the funnel plot appeared to be asymmetric, with some missingness at the lower right portion of the plot, suggesting possible publication bias (Supplementary Figure S1).

The CRP levels were reduced after $H$. pylori eradication not only in healthy subjects [34] but also in subjects with diabetes mellitus [25], rheumatoid arthritis [26], non-alcoholic hepatitis [33], and cirrhosis [35]. From the results of the overall meta-analysis, $H$. pylori eradication was associated with reduced CRP levels (SMD $=-0.64 ; 95 \% \mathrm{Cl}$ : -1.02 to $-0.27 ; I^{2}=89 \%$, Figure 2 ). In a subgroup analysis by study designs, the reduction of CRP in the eradicated patients was not found in the group of RCTs, while it was found in the group of before-after studies (Figure 3).

In additional subgroup analysis by comorbidity (such as glucose intolerance/diabetes, rheumatoid arthritis, chronic liver disease), H. pylori eradication reduced the CRP levels in both patients with and without comorbidities (Supplementary Figure S2). In a subgroup analysis by country (which can reflect ethnicity), $H$. pylori eradication reduced the CRP levels in patients in Europe and the Middle East, while this seemed to be an insufficient analysis because there was only one report in the United States or Asia (Korea) (Supplementary Figure S3). In a subgroup analysis by the follow-up period,
H. pylori eradication reduced the CRP levels more in patients with $\geq 3$-month periods relative to those with $<3$-month periods (Supplementary Figure S4).

\section{Discussion}

The overall meta-analysis revealed that $H$. pylori eradication was associated with reduced CRP levels. However, the result was not similarly supported by a subgroup of the RCTs, which meant that the evidence as regards the effects of $H$. pylori eradication on the reduction of CRP levels was weak. As a systemically low-grade inflammation, as expressed by the CRP level, is related to the development and progression of various diseases [11], the present study findings would promote our understanding of the pathophysiology.

Although the present study does not mention the etiological mechanisms responsible for the relationship between CRP and $H$. pylori eradication, several potential factors involved have been assumed. The mucosal response to $H$. pylori infection induces the production of cytokines (e.g. interleukin-6, tumor necrosis factor- $\gamma$ ) on CRP, mainly in the liver hepatocytes $[36,37]$. H. pylori eradication suppresses the cytokine production, which can reduce the CRP level [38]. The microbiome is a possible contributor as the diverse microbiome is thought to modulate inflammation and the host's immune system favorably [39-41]. A microbiome lacking in the diversity due to infection can induce metabolic endotoxemia with an increased CRP level $[40,41]$. The anti-biotic therapies against $H$. pylori infection alter the microbiome, leading to a reduction in $H$. pylori-induced inflammation [42, 43].

Furthermore, the clinical manifestations of some chronic diseases may be improved in association with the reduced CRP levels [17, 18]. While it is not fully clarified whether CRP is the 


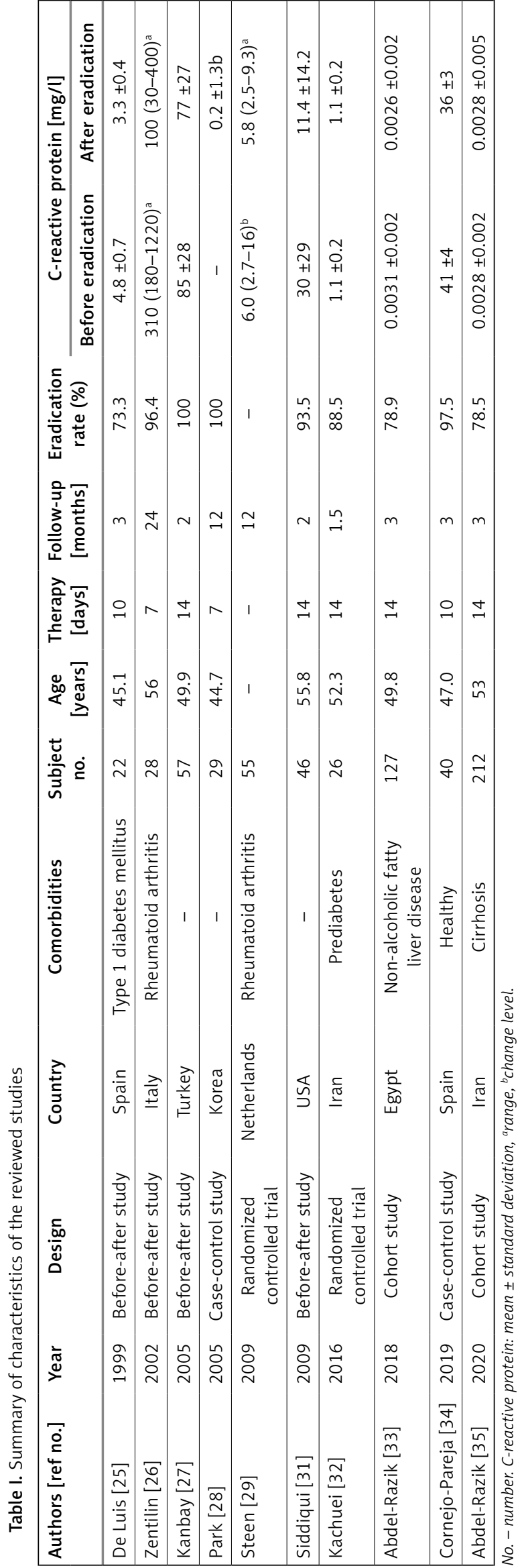

etiological agent of inflammation or a simple indicator/marker related to inflammation [11, 44], the pathophysiology of chronic diseases appears to be generally improved in a relatively long period. When the subanalysis by the follow-up period of eradicated patients was conducted, the CRP levels were more reduced in the patients with a longer follow-up period (as shown in (Supplementary Figure S4). Future work on the relationship of CRP and clinical manifestations with the period after $H$. pylori eradication may shed light on the etiological mechanisms.

The present study had some strengths. First, the CRP levels were analyzed before and after $H$. pylori eradication among the same individuals. Accordingly, the individual characteristics were not likely to have had a large effect on the results. Second, the duplicate assessments were performed for the eligibility, risk of bias and data abstraction in the review process.

There were some study limitations. First, circulating CRP levels can be associated with age, gender, ethnicity, lifestyle and comorbidity [45], although few within-person variations of CRP are revealed at the year-to-year level [46]. The subanalysis by comorbidity and country did not reveal a clear difference in the results (as shown in (Supplementary Figures S2 and S3), while the other factors of age, gender and lifestyle were not collected in the original studies used in the present meta-analysis. Second, there was a small number of original studies (especially RCTs) with not very large numbers of participants and some different follow-up periods; thus, the present study integrated the different study designs, which might undermine the meta-analysis. Third, although the measurement methods of CRP could differ across studies, many studies did not describe the methods. Thus, we did not conduct a subanalysis according to the methods, but we assumed that the studies usually did not change the methods of measuring the CRP levels before and after eradication. Fourth, the funnel plot asymmetry to detect publication bias in the literature might slightly overestimate the effect sizes. The present study findings must be carefully interpreted with these limitations, which will be addressed as the next challenge.

In conclusion, the overall meta-analysis demonstrated that $H$. pylori eradication was associated with reduced CRP levels; however, the result was not supported by a subgroup of the RCTs. Weak evidence exists regarding the effects of $H$. pylori eradication on CRP levels. Further research is warranted.

\section{Conflict of interest}

The authors declare no conflict of interest. 
Table II. Quality scores for the reviewed randomized studies

\begin{tabular}{|lcccccc|}
\hline $\begin{array}{l}\text { Authors } \\
\text { [ref no.] }\end{array}$ & $\begin{array}{c}\text { Bias arising } \\
\text { from the } \\
\text { randomization } \\
\text { process }\end{array}$ & $\begin{array}{c}\text { Bias due } \\
\text { to deviations } \\
\text { from intended } \\
\text { interventions }\end{array}$ & $\begin{array}{c}\text { Bias due } \\
\text { to missing } \\
\text { outcome } \\
\text { data }\end{array}$ & $\begin{array}{c}\text { Bias } \\
\text { in measurement } \\
\text { of the outcome }\end{array}$ & $\begin{array}{c}\text { Bias } \\
\text { in selection } \\
\text { of the reported } \\
\text { results }\end{array}$ & $\begin{array}{c}\text { Overall } \\
\text { risk } \\
\text { of bias }\end{array}$ \\
\hline Steen [29] & $\begin{array}{c}\text { Some } \\
\text { concerns }\end{array}$ & Low & Low & Low & $\begin{array}{c}\text { Some } \\
\text { concerns }\end{array}$ & $\begin{array}{c}\text { Some } \\
\text { concerns }\end{array}$ \\
\hline Kachuei [32] & $\begin{array}{c}\text { Some } \\
\text { concerns }\end{array}$ & Low & $\begin{array}{c}\text { Some } \\
\text { concerns }\end{array}$ & Low & $\begin{array}{c}\text { Some } \\
\text { concerns }\end{array}$ & $\begin{array}{c}\text { Some } \\
\text { concerns }\end{array}$ \\
\hline
\end{tabular}

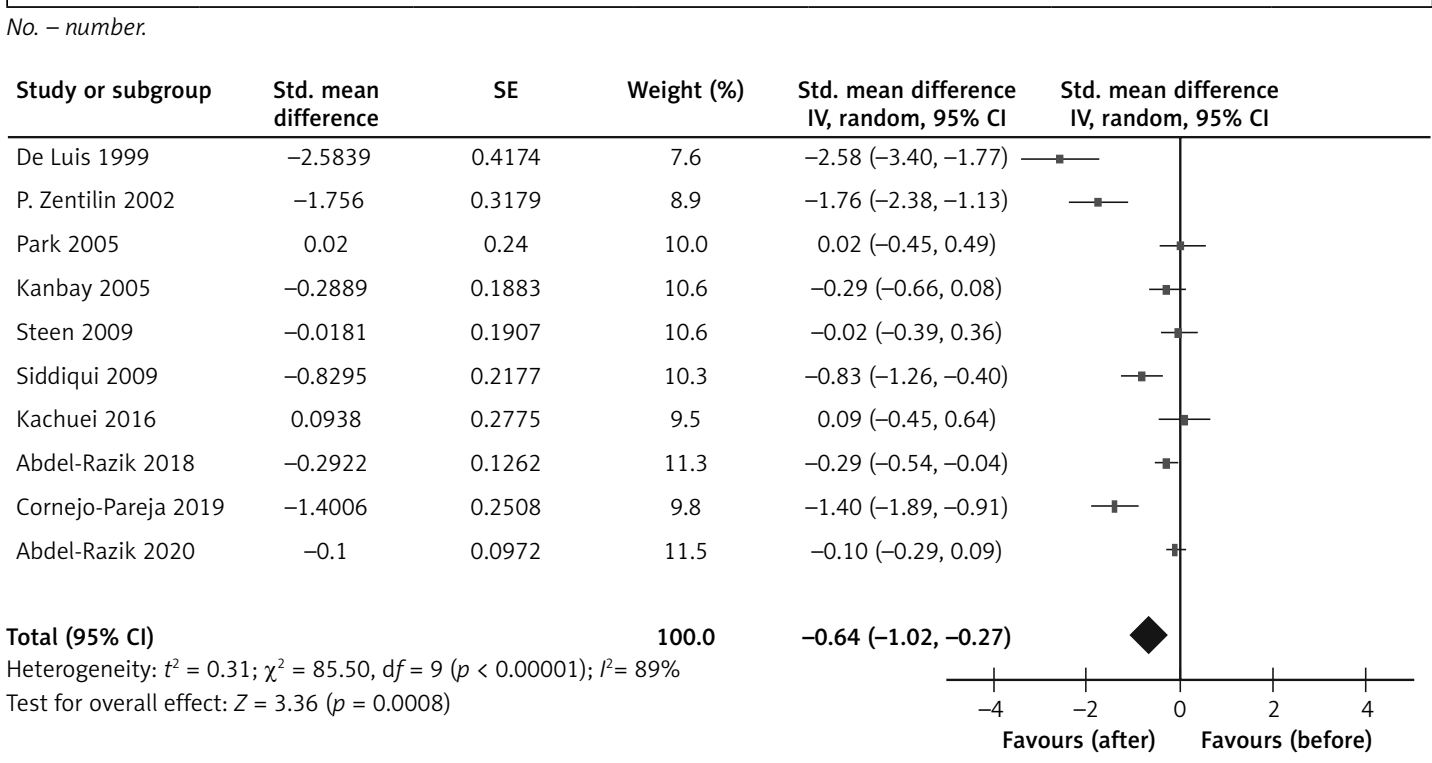

Figure 2. Forest plot of the change in the C-reactive protein level after Helicobacter pylori eradication

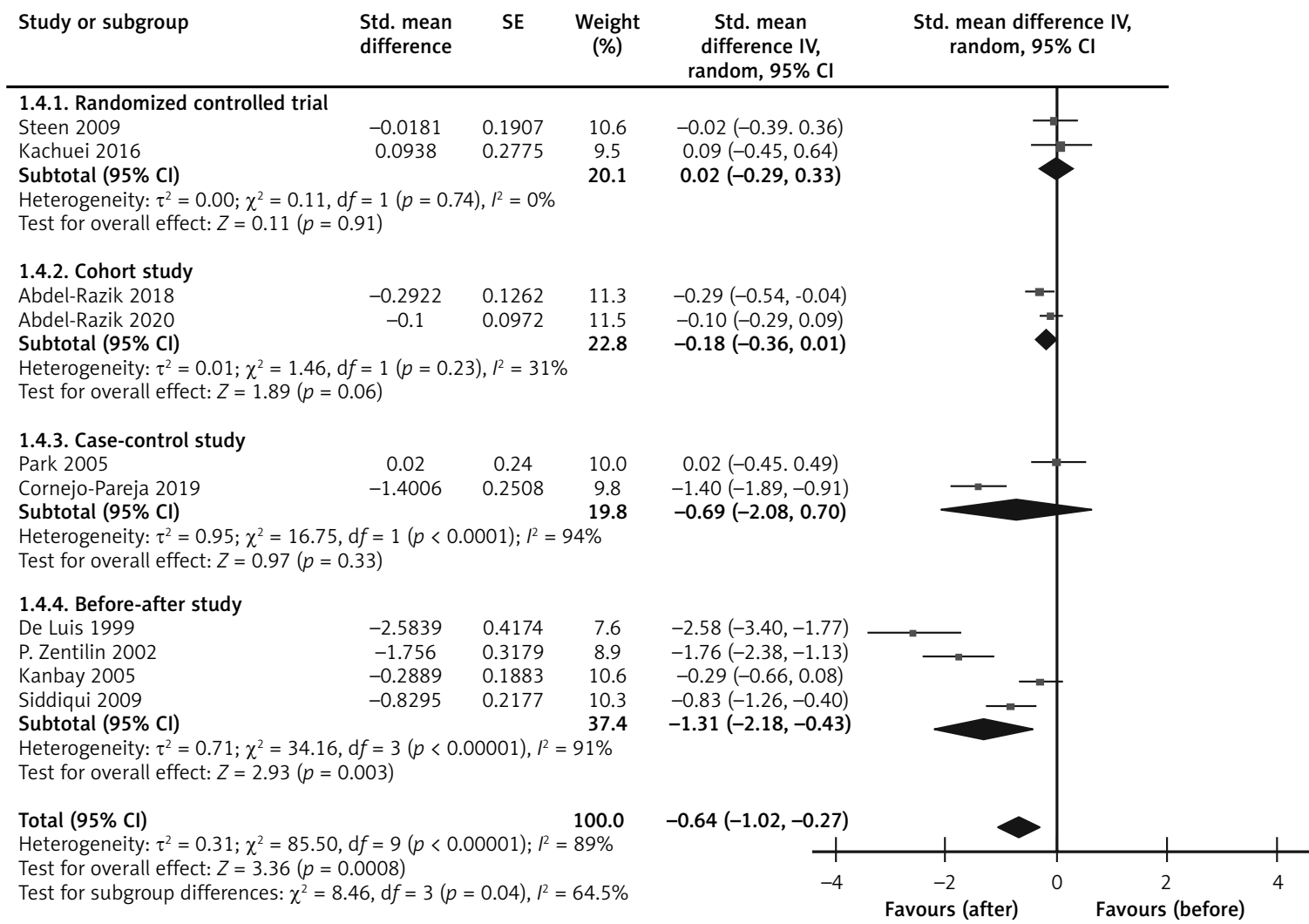

Figure 3. Subgroup analysis by study designs 


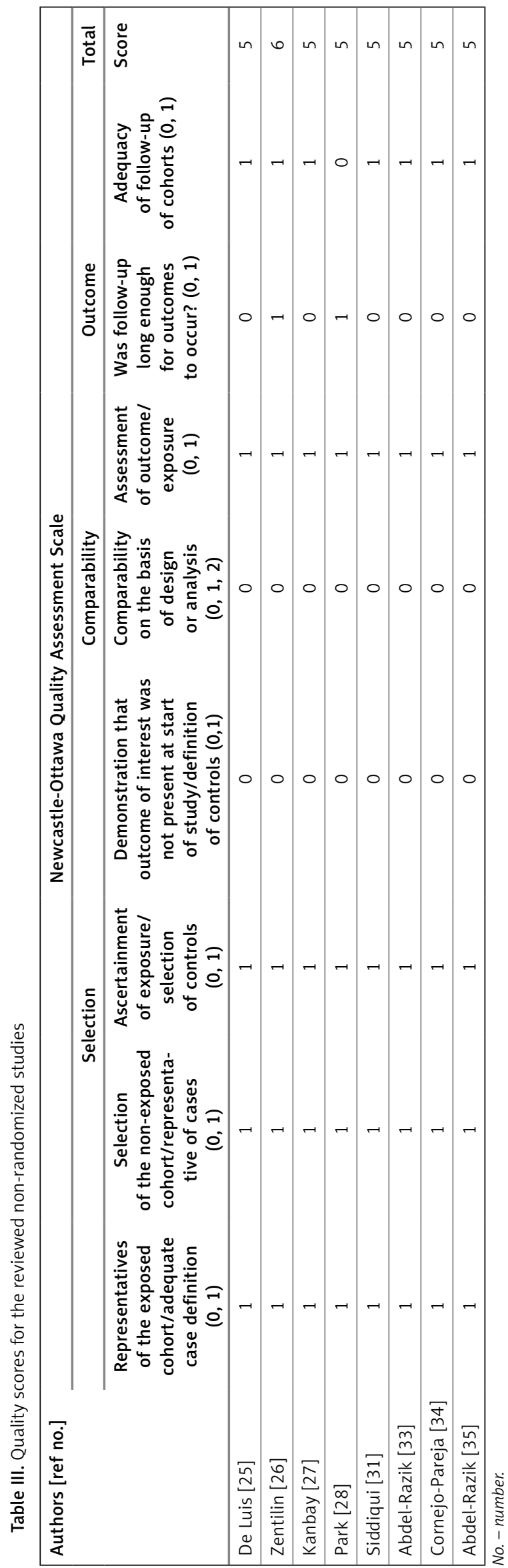

\section{References}

1. Chey WD, Leontiadis GI, Howden CW, Moss SF. ACG Clinical Guideline: treatment of Helicobacter pylori infection. Am J Gastroenterol 2017; 112: 212-39.

2. Thorell K, Lehours P, Vale FF. Genomics of Helicobacter pylori. Helicobacter 2017; 22: 10.

3. Warren JR, Marshall B. Unidentified curved bacilli on gastric epithelium in active chronic gastritis. Lancet 1983; 1: 1273-5.

4. Kato M, Ota H, Okuda M, et al. Guidelines for the management of Helicobacter pylori infection in Japan: 2016 Revised Edition. Helicobacter 2019; 24: e12597.

5. Banks M, Graham D, Jansen M, et al. British Society of Gastroenterology guidelines on the diagnosis and management of patients at risk of gastric adenocarcinoma. Gut 2019; 68: 1545-75.

6. Fallone CA, Chiba N, van Zanten SV, et al. The Toronto consensus for the treatment of Helicobacter pylori infection in adults. Gastroenterology 2016; 151: 51-69.

7. C Reactive Protein Coronary Heart Disease Genetics Collaboration (CCGC), Wensley F, Gao P, et al. Association between $C$ reactive protein and coronary heart disease: Mendelian randomisation analysis based on individual participant data. BMJ 2011; 342: d548.

8. Kluft C, de Maat MP. Sensitive markers of inflammation make it possible to study the chronic process: the rise of interest in low levels of C-reactive protein. Vascul Pharmacol 2002; 39: 99-104.

9. Yücel Ç, Omma A, Sertoğlu E, et al. Evaluation of atherogenic laboratory markers in Behçet's disease patients with vascular involvement. Arch Med Sci 2019; 16: 531-7.

10. Saribas S, Kocazeybek B, Aslan M, et al. Do procalcitonin and $\mathrm{C}$-reactive protein levels have a place in the diagnosis and follow-up of Helicobacter pylori infections? J Med Microbiol 2004; 53: 639-44.

11. Schett G, Neurath MF. Resolution of chronic inflammatory disease: universal and tissue-specific concepts. Nat Commun 2018; 9: 3261.

12. Whincup PH, Mendall MA, Perry IJ, Strachan DP, Walker M. Prospective relations between Helicobacter pylori infection, coronary heart disease, and stroke in middle aged men. Heart 1996; 75: 568-72.

13. Kowalski M. Helicobacter pylori (H. pylori) infection in coronary artery disease: influence of $\mathrm{H}$. pylori eradication on coronary artery lumen after percutaneous transluminal coronary angioplasty. The detection of H. pylori specific DNA in human coronary atherosclerotic plaque. J Physiol Pharmacol 2001; 52 (1 Suppl): 3-31.

14. Longo-Mbenza B, Mambune HF, Kasiam JB, et al. Relationship between waist circumference and cholesterol in Central Africans with congestive heart failure. West Afr J Med 2007; 26: 183-90.

15. Ražuka-Ebela D, Giupponi B, Franceschi F. Helicobacter pylori and extragastric diseases. Helicobacter 2018; 23 : e12520.

16. Fang Y, Fan C, Xie H. Effect of Helicobacter pylori infection on the risk of acute coronary syndrome: a systematic review and meta-analysis. Medicine 2019; 98: e18348.

17. Kolkhir P, Altrichter S, Hawro T, Maurer M. C-reactive protein is linked to disease activity, impact, and response to treatment in patients with chronic spontaneous urticaria. Allergy 2018; 73: 940-8.

18. Umemura A, Oeda T, Yamamoto K, et al. Baseline plasma $\mathrm{C}$-reactive protein concentrations and motor prognosis in Parkinson disease. PLoS One 2015; 10: e0136722. 
19. Sterne JAC, Savović J, Page MJ, et al. RoB 2: a revised tool for assessing risk of bias in randomised trials. BMJ 2019; 366: 14898.

20. Wells G, Shea B, O'Connell D, et al. Ottawa Hospital Research Institute. The Newcastle-Ottawa Scale (NOS) for assessing the quality of nonrandomized studies in meta-analyses. 2011. http://www.ohri.ca/programs/clinical_epidemiology/oxford.asp [Accessed 21 September 2020].

21. Higgins JPT, Thomas J, eds. Cochrane handbook for systematic reviews of interventions, version 6. 2019. https:// training.cochrane.org/handbook/current [Accessed 4 June 2020].

22. Kushner I, Rzewnicki D, Samols D. What does minor elevation of C-reactive protein signify? Am J Med 2006; 119: 166.

23. Goudet SM, Bogin BA, Madise NJ, Griffiths PL. Nutritional interventions for preventing stunting in children (birth to 59 months) living in urban slums in low- and middle-income countries (LMIC). Cochrane Database Syst Rev 2019; 6: CD011695.

24. Jayaraman S, Sethi D, Wong R. Advanced training in trauma life support for ambulance crews. Cochrane Database Syst Rev 2014; 2014: CD003109.

25. de Luis DA, Garcia Avello A, Lasuncion MA, et al. Improvement in lipid and haemostasis patterns after Helicobacter pylori infection eradication in type 1 diabetic patients. Clin Nutr 1999; 18: 227-31.

26. Zentilin P, Seriolo B, Dulbecco P, et al. Eradication of Helicobacter pylori may reduce disease severity in rheumatoid arthritis. Aliment Pharmacol Ther 2002; 16: 1291-9.

27. Kanbay M, Gür G, Yücel M, Yilmaz U, Boyacioğlu S. Does eradication of Helicobacter pylori infection help normalize serum lipid and CRP levels? Dig Dis Sci 2005; 50: 1228-31

28. Park SH, Jeon WK, Kim SH, et al. Helicobacter pylori eradication has no effect on metabolic and inflammatory parameters. J Natl Med Assoc 2005; 97: 508-13.

29. Steen KS, Lems WF, Visman IM, et al. The effect of Helicobacter pylori eradication on C-reactive protein and the lipid profile in patients with rheumatoid arthritis us ing chronic NSAIDs. Clin Exp Rheumatol 2009; 27: 170.

30. Pellicano R, Oliaro E, Fagoonee S, et al. Clinical and biochemical parameters related to cardiovascular disease after Helicobacter pylori eradication. Int Angiol 2009; 28: 469-73.

31. Siddiqui NR, Garvey WT, Khaled MA. H. pylori-induced higher C-reactive protein in obese African Americans. Artery Res 2009; 3: 39-42.

32. Kachuei A, Amini M, Sebghatollahi V, Feizi A, Hamedani P, Iraj B. Effect of Helicobacter pylori eradication on in sulin resistance among prediabetic patients: a pilot study and single-blind randomized controlled clinical trial. I Res Med Sci 2016; 21: 8

33. Abdel-Razik A, Mousa N, Shabana W, et al. Helicobacter pylori and non-alcoholic fatty liver disease: a new enigma? Helicobacter 2018; 23: e12537.

34. Cornejo-Pareja I, Martín-Núñez GM, Roca-Rodríguez MM, et al. H. pylori eradication treatment alters gut microbiota and GLP-1 secretion in humans. J Clin Med 2019; 8: 451.

35. Abdel-Razik A, Mousa N, Elhelaly R, et al. Helicobacter pylori as an initiating factor of complications in patients with cirrhosis: a single-center observational study. Front Med 2020; 7: 96.

36. Figueiredo CA, Marques CR, Costa Rdos S, da Silva HB, Alcantara-Neves NM. Cytokines, cytokine gene poly- morphisms and Helicobacter pylori infection: friend o foe? World J Gastroenterol 2014; 20: 5235-43.

37. Blosse A, Lehours P, Wilson KT, Gobert AP. Helicobacter: Inflammation, immunology, and vaccines. Helicobacter 2018; 23: e12517.

38. Lee HN, Na HK, Surh YJ. Resolution of inflammation as a novel chemopreventive strategy. Semin Immunopathol 2013; 35: 151-61.

39. Honda K, Littman DR. The microbiota in adaptive im mune homeostasis and disease. Nature 2016; 535: 75 84.

40. Belkaid Y, Hand TW. Role of the microbiota in immunity and inflammation. Cell 2014; 157: 121-41.

41. Xiao S, Zhao L. Gut microbiota-based translational biomarkers to prevent metabolic syndrome via nutritional modulation. FEMS Microbiol Ecol 2014; 87: 303-14.

42. Brawner KM, Kumar R, Serrano CA, et al. Helicobacter pylori infection is associated with an altered gastric microbiota in children. Mucosal Immunol 2017; 10: 1169-77.

43. Rolig AS, Cech C, Ahler E, Carter JE, Ottemann KM. The degree of Helicobacter pylori-triggered inflammation is manipulated by preinfection host microbiota. Infect Immun 2013; 81: 1382-9.

44. Sproston NR, Ashworth JJ. Role of C-reactive protein at sites of inflammation and infection. Front Immunol 2018; 9: 754

45. de Maat MP, Kluft C. Determinants of C-reactive protein concentration in blood. Ital Heart J 2001; 2: 189-95.

46. Emberson JR, Whincup PH, Morris RW, Walker $M$ Lowe GD, Rumley A. Extent of regression dilution for established and novel coronary risk factors: results from the British Regional Heart Study. Eur J Cardiovasc Prev Rehabil 2004; 11: 125-34 